\title{
HPV positivity varies with technique and primer set, in formalin-fixed paraffin-embedded benign and malignant breast tissue from Malta
}

\author{
Roderick Mallia ${ }^{1}$, Jean-Paul Mangion ${ }^{1}$, Christian Camenzuli ${ }^{1}$, Annalisse Cassar ${ }^{1}$, Paul Cacciottolo ${ }^{1}$, \\ John Cauchi ${ }^{1}$, Joseph Borg ${ }^{2}$, Sarfraz Ali ${ }^{1}$, Pierre Schembri-Wismayer ${ }^{{ }^{*}}$
}

${ }^{1}$ Anatomy Department, University of Malta, Msida, Malta;
${ }^{2}$ Applied Biomedical Sciences Department, University of Malta, Msida, Malta;
Email: ${ }^{*}$ pierre.schembri-wismayer@um.edu.mt

Received 14 June 2011; revised 20 July 2011; accepted 19 August 2011.

\begin{abstract}
The role of human papillomavirus in breast cancer pathogenesis is an area of considerable debate following differing results from all over the world. This study analyzed paraffin embedded tissue from 19 patients with benign or malignant breast disease. Standard PCR with GP5+/6+ and FAP primers, proved negative in all cases. However, qRT-PCR using the SF10 primer set detected HPV DNA in 2 out of these samples. Whilst our data does not support a major role for HPV in the pathogenesis of breast disease in Malta, it definitely does not exclude it totally. This study also clearly shows that the method of analysis is one of the variables resulting in the range of differing results witnessed worldwide in this area of study.
\end{abstract}

Keywords: Human Papillomavirus (HPV); Breast Cancer; Benign; qRT-PCR

\section{INTRODUCTION}

Unlike its Mediterranean neighbors which show amongst the lowest cancer incidences and mortalities in Europe, Malta shows a cancer mortality more characteristic of countries of North Western Europe, and an incidence midway between that of Northern and Mediterranean nations [1]. This may possibly be a result of its long British colonialism and the influence of the British as opposed to the Mediterranean diet. Malta's females are known to be amongst the most obese in Europe $[1,2]$ and there are clear cut correlations between obesity, metabolic syndrome and breast cancer risk [3,4]. Cervical cancer incidence in Malta, on the other hand, is the lowest in the European Union according to the same 2008 European statistics [1]. One can therefore surmise from this epidemiological data that it is unlikely that Human
Papillomavirus (HPV) plays a predominant role in breast cancer in Malta.

HPV DNA is found in almost $100 \%$ of cervical cancers and ano-genital warts and has been detected in various other tumors including tumors of the anal canal, mouth, pharynx, esophagus and larynx [5].

Over the last decade, several studies have looked into the possibility of HPV involvement in breast cancers and some have also looked at benign breast tissues [6] with very mixed results.

With no obvious differences in the methods of analysis, some have found no HPV DNA and others have found varying amounts of HPV positivity up to $86 \%$ [7].

More recent studies have shown that HPV DNA can be detected in a number of breast cancer cell lines [8] and also that koilocytes, the cells typical of HPV infection in cervical intraepithelial neoplasia, can be found in breast cancers [9].

In vitro studies have shown that oncogenic proteins of the high risk human papillomaviruses are capable of immortalizing human mammary epithelial cells [10] and these oncogene products have also been shown to synergize with p53 mutations and estrogen in inducing breast cancer in animal models [11].

A recent study from Italy showed the expression of human papillomavirus DNA in 3 out of 5 juvenile breast cancers in teenagers and young women [12]. In this same study, all HPV positive cases were homozygous for a p53 polymorphism known to be associated with an HPV-linked cancer risk.

Despite all this evidence, large studies from countries with high levels of anogenital HPV-associated cancer prevalence are still showing total negativity in large numbers of patients even using sensitive techniques such as quantitative real time polymerase chain reaction (qRT-PCR) [13]. Closer to Malta, a recent study of Tunisian patients also showed no detection of HPV DNA 
[14].

One can also consider whether such HPV positivity is a feature of all tumorigenesis or only specifically associated with malignancy. A study in Brazilian women found no HPV in benign breast disease but did find HPV in $25 \%$ of patients with breast carcinoma [6]. However, this study was done using HPV 16 and HPV 18-specific primers and did not aim to detect all HPV subtypes.

For this reason, our sample included both breast cancers as well as benign breast lumps to see whether any benign tumors may also be positive for any kind of HPV.

\section{MATERIALS AND METHODS}

\subsection{DNA Isolation}

Samples from breast tumour tissue for Human Papillomavirus analysis were obtained from the archives of the Pathology Department, St. Luke's Hospital, G'Mangia. Formalin-fixed paraffin-embedded samples from breast lumpectomies or mastectomies were chosen. Skin and nipple samples were not studied since these do not necessarily correlate to breast cancer pathogenesis. The list of actual pathologies is shown in Table 1. These diagnoses however were kept hidden by one of us (S.A.) from the rest who were doing the HPV detection. The formalin-fixed paraffin-blocks were sectioned at the histology laboratory of St. Luke's Hospital, G'Mangia. Care was taken during sectioning to avoid any contamination between samples, and the microtome was cleaned thoroughly between samples. DNA extraction from the paraffin-embedded tissues was performed according to the method suggested by Tseng et al. [15]. Briefly three 50 $\mu \mathrm{m}$ thick sections were placed in a sterile $1.5 \mathrm{~mL}$ microcen-trifuge tube filled with $400 \mu \mathrm{L}$ lysis buffer that consisted of $10 \mathrm{mM}$ Tris-HCL, pH 8.3; $50 \mathrm{mM} \mathrm{KCl} ; 2.5$ $\mathrm{mM} \mathrm{MgCl}_{2}$ and $0.45 \%$ Tween 20. Such tubes were placed in a water bath for incubation at $70^{\circ} \mathrm{C}$ for 1 hour to melt the paraffin. The samples were then centrifuged at $16,000 \mathrm{~g}$ for 5 minutes at room temperature. The paraffin solidified on top of the buffer and was removed from the tube with a sterile pipette tip (new one for each sample). The tubes were then incubated at $60^{\circ} \mathrm{C}$ for 2 hours after the addition of $20 \mu \mathrm{L}$ proteinase $\mathrm{K}(20$ $\mathrm{mg} / \mathrm{mL}$ ). Each tube was vortexed to suspend the tissue pellet after another $10 \mu \mathrm{L}$ proteinase $\mathrm{K}$ was added and digested at $55^{\circ} \mathrm{C}$ for 2 hours. To inactivate the proteinase $\mathrm{K}$ after digestion, the samples were boiled for $10 \mathrm{~min}$ utes and then centrifuged at $16,000 \mathrm{~g}$ for 5 minutes, through a microconcentrator (Microcon YM30). The microconcentrator column was inverted and spun inversely to release the DNA. The liquid was pipetted into a new sterile microcentrifuge tube and the final volume adjusted to $100 \mu \mathrm{l}$ for each specimen by the addition of TE buffer containing RNAse. DNA obtained in this way was quality tested using standard spectrophotometric methods.

\subsection{Standard PCR}

DNA (50 ng - $100 \mathrm{ng}$ ) of each sample was amplified by polymerase chain reaction (PCR). The primers used for amplifications were those used in a previous paper which detected high levels of HPV in breast cancer samples, thus ensuring the greatest chances of success [7]. The primers PC03 and PC04 were used to amplify a 110 bp fragment of the $\beta$-globin gene as described previously [16]. Papillomavirus sequences were amplified by two different reactions, each targeting highly conserved regions within the L1 open reading frame of papillomaviruses.

These used the GP5+/GP6+ primers and the FAP primers respectively as had been described in previous publications $[17,18]$. These primer combinations amplify large numbers of individual HPV types. Amplification with the GP primers was performed in $2 \mathrm{mM} \mathrm{MgCl}_{2}$ using 40 cycles at an annealing temperature of $40^{\circ} \mathrm{C}$. The expected size of the amplicon was $140-150 \mathrm{bp}$.

The FAP primer reaction gave a product of expected size 480 bp after 45 cycles in $3.5 \mathrm{mM} \mathrm{MgCl} 2$ with an annealing temperature of $50^{\circ} \mathrm{C}$. Apart from Breast biopsy or lumpectomy specimens, a positive control of DNA from a cervical carcinoma was used and HL60 DNA was as a negative control.

The PCR products were examined using $1 \%$ agarose gel electrophoresis in 1x TAE buffer solution and stained with ethidium bromide to verify the presence of amplified DNA in the samples. A 50 bp ladder (Sigma) was used for size comparisons.

Table 1. Histological Diagnosis of Breast samples

\begin{tabular}{cc}
\hline Sample & Histological Diagnosis \\
\hline $1,4,8,10,12,14,15,17,18,19$ & Infiltrating ductal carcinoma \\
& Intraductal carcinoma \\
$3,6,7$ & Fibroadenoma \\
$5,9,13$ & Fibrocystic disease \\
& \\
2 & Intraductal papilloma \\
& \\
& Carcinoma cervix \\
&
\end{tabular}




\section{3. qRT-PCR}

100ng of DNA from each sample was also amplified by means of RT-PCR on an ABI 7300 Real time PCR system using EVAgreen mix (Solis Biodyne). The SF10 primer set (which also amplify the L1 open reading frame), was used to make sure all variants of HPV genome are amplified and reaction conditions were modified from a previously published study [19]. Briefly, amplifications were performed in $25 \mu \mathrm{l}$ reactions with forward and reverse primer concentrations at $100 \mathrm{nM}$. Thermal cycling was $95^{\circ} \mathrm{C}$ for 15 minutes followed by 45 cycles at $95^{\circ} \mathrm{C}$ for $15 \mathrm{~s}$ and $60^{\circ} \mathrm{C}$ for $30 \mathrm{~s}$.

Glyceraldehyde-3-phosphate dehydrogenase (GAPDH) was also amplified with the same cycle parameters but with primers at a concentration of $300 \mathrm{nM}$ as an internal control. Serial ten fold dilutions of HeLa DNA equivalent to 2.5, 25,250 and $2500 \mathrm{HPV}$ genomes (based on a average content of 25 genomes per HeLa cell) were used to assess the accuracy of the amplification.

\section{RESULTS}

\subsection{Standard PCR}

$\beta$-globin amplification showed that all samples with the exception of sample 18 had good quality DNA and no inhibitors that would block a PCR reaction. $\beta$-globin genomic DNA was successfully amplified from all other samples (see Figure 1).

Amplification with both GP5+/GP6+ as well as with FAP primers only resulted in a PCR product in the case of the positive control cervical carcinoma. All other samples were negative (Figures 2,3). Thus in the case of the infiltrating carcinomas, intraductal tumors as well as benign tumors and fibrocystic disease, no HPV DNA positivity could be detected by means of standard PCR using the same primers which allowed a detection rate of $86 \%$ in a previous study.

Similarly there was no difference between samples coming from patients of differing ages.

All samples were taken from tumours prior to treatment but five out of the 19 samples had had a previous fine needle aspiration biopsy. This previous communication between the surface skin and the tumor by the biopsy needle tract did not make any difference when it came to tumor HPV positivity.

None of the patients had had any cervical cancers or ano-genital warts sent for histological analysis so the study cannot analyze any issues of possible systemic spread.

\subsection{Quantitative Real Time PCR}

GAPDH was adequately amplified from each sample but HPV DNA was also amplified from two samples - sample

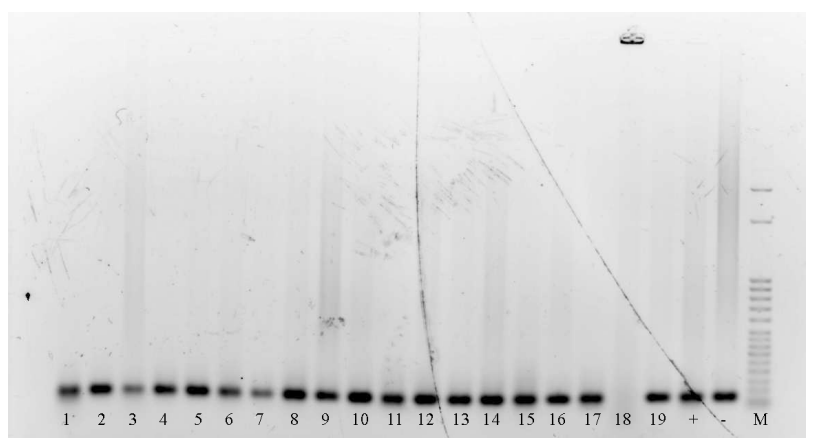

Figure 1. PCR of $\beta$-globin DNA from all samples. + is positive control, - is negative control and $\mathrm{M}$ is $50 \mathrm{bp}$ marker.

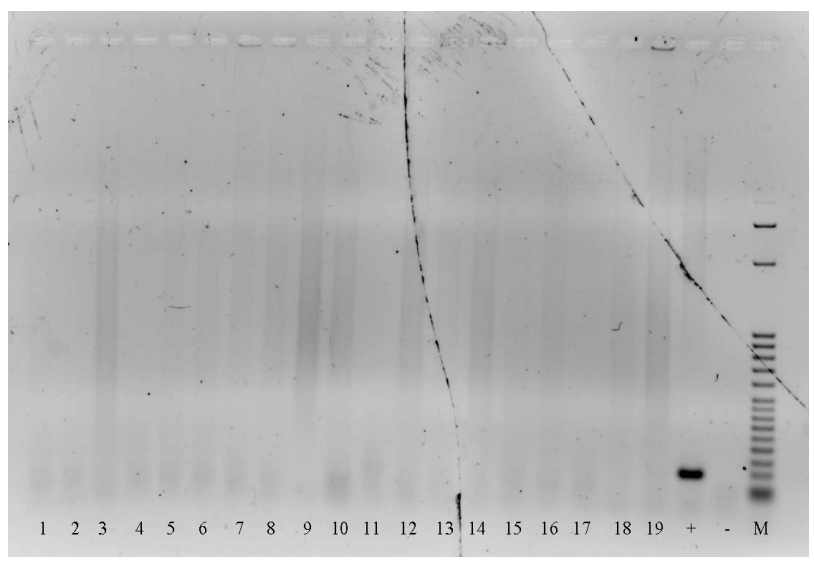

Figure 2. Amplification of HPV DNA with GP primers.

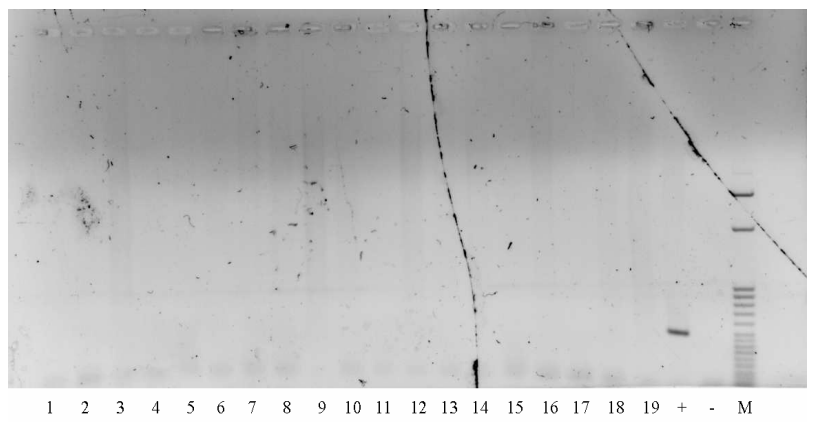

Figure 3. Amplification of HPV DNA with FAP primers.

11 and sample 12. These are both carcinoma samples and indicate that in a small percentage of cases, a few copies of the HPV genome are in fact detectable in the DNA isolated from Maltese breast cancer tissue. Using this more sensitive method, the HPV DNA positive breast disease samples are detected in 0.11 of cases (CI of 0 to 0.25 at $\mathrm{p}=0.05$ ).

\section{DISCUSSION}

This present study, despite being a small one, analyzes a representative sample of the approximately 250 breast cancers detected annually in Malta [1]. Whilst we showed no HPV positivity by means of standard PCR 
using GP5+/6+ and FAP primers which had shown high levels of HPV positivity in other studies, qRT-PCR using the combined SPF10 primer set did detect considerable amount of HPV positivity in a couple of our samples. This latter primer set was specifically designed for highly sensitive broad-spectrum detection of ano-genital HPV [20] and has been used for HPV detection in difficult samples such as urine [19]. It may be well worth while to extend our research to follow up this research with a larger number of fresh samples, analyzed by qRT-PCR and make use of in situ PCR techniques on histological sections so as to see whether our results are indicative of a larger presence of HPV DNA in Maltese breast cancers.

This variability of results regarding HPV DNA positivity in breast cancer samples is a recent dilemma in molecular virology. One may imagine that sensitivity of methods, different primer sets, different sexual behavioral patterns, differing incidences of ano-genital HPV infection and possibly different population genetics could play a role in these differing results.

A recent study on a large number of breast cancer patients in India has not shown HPV positivity [13] despite the fact that this country has a much higher level of ano-genital HPV, and associated social risk factors for this infection than in many western nations where breast cancer HPV positivity has been found [21]. This also tends to counter the suggestion that HPV can spread from cervix to breast internally through the bloodstream, despite one interesting study which showed high positivity rates of HPV DNA in breast lesions when there was a history of cervical intraepithelial neoplasia [22]. A more recent study has shown HPV positivity in menstrual blood in the presence of cervical intraepithelial neoplasia [23]. Even though psychosexual factors have been suggested as being a cause for different outcomes, relating to direct external spread from genital region to breast, both positive and negative results have been obtained from various European and Western nations between which one would not expect drastic differences in sexual behavior [24,25].

That different background genetics is coming into play is an important and intriguing argument. However, there are studies from both Austria and the USA, which show either positive or negative results suggesting that this is not the only variable [7,26-28]. The recent Italian study of HPV involvement in juvenile breast cancer certainly points to the possibility of genetic susceptibility playing a role at least in these cases [12].

In Malta, studies on children in a small fishing village have shown that infective susceptibility genes can exist even in a small population, most probably through a genetic founder effect $[29,30]$. However whilst this may well explain certain cases of abnormal juvenile breast cancer, as in the Italian study [12], it is unlikely to be responsible for the greatly varying results seen worldwide between different studies.

The differing primer combinations used may definitely play a role although how much is open to question. In our study, during standard PCR, we have used two of the three primer sets used by de Villiers, the study with highest positivity of HPV detected [7]. Similarly the recently published large Indian study [13] also used one of these same primer sets and both studies came out as totally negative. It should be mentioned that the Indian study also used these same primers for qRT-PCR, which should be even more sensitive as a detection technique.

It is interesting to note that the study by de Villiers $e t$ al., detected primarily the HPV 11 subtype most commonly associated with benign ano-genital viral warts as opposed to the high risk types associated with anogenital cancer [7].

On the other hand, our qRT-PCR analysis amplified HPV DNA in two out of nineteen samples, indicating that the SF10 primer combination may be able to amplify sequences that the GP and FAP consensus primers miss.

Although it is not easy to contemplate, differences in these studies may have to do with preparation methods used for samples.

Although one would require more details to be able to make an accurate analysis, it is clear that most studies showing HPV DNA positivity use paraffin embedded samples with sections cut out of paraffin blocks [6,7,22,25,28,31-33].

On the other hand the two largest studies, which are negative for HPV DNA, were in fact performed directly on fresh tumour tissue [34,35], where the risk of the sectioning and deparaffinising processes in producing contamination of samples is removed. Other studies includeing ours have found largely negative results despite using paraffin block based sections [36] so it is not a clear distinction.

Unfortunately various points about how samples are collected - for example if they are all sectioned as a single consecutive run of samples with cleaning of the blade between each sample - as was the case for our study - are not usually published. If, on the other hand, sections are produced as part of the general procedures of a busy lab that is handling repeated pathological samples that are HPV positive, then this could be a risk.

Similarly, our study used a method of deparafinisation without using xylene or other organic solvents and carried out as a separate study in a small academic lab. If this deparafinsation is happening as a standard practice as part of a busy clinical lab using large amounts of organic solvents, this may again be a possible source of 
contamination - once again - this aspect of procedures is not usually clarified in the materials and methods sections of most such papers.

Whilst this dilemma will no doubt continue for some time yet, our small study does not suggest that HPV is a major pathologic determinant in Maltese breast disease.

\section{ACKNOWLEDGEMENTS}

We would like to thanks Fiona Sammut of the department of statistics for statistical support.

\section{REFERENCES}

[1] Steliarova-Foucher, E., Lortet-Tieulent, J. and Ferlay, J. (2010) European cancer observatory. Clininfo Reference, 46, 765-781.

[2] Wieland, U., Johansson Augier, A., Fritz, M. and Feith, M. (2007) Europe in figures eurostat workbook. Schäfer, G. 2007. Ref Type: Report.

[3] Rosato, V., Bosetti, C., Talamini, R., Levi, F., Montella, M., Giacosa, A., Negri, E. and La, V.C. (2011) Metabolic syndrome and the risk of breast cancer in postmenopausal women. Annals of Oncology, 22, 2157-2159.

[4] Gonzalez, C.A. and Riboli, E. (2010) Diet and cancer prevention: Contributions from the European Prospective Investigation into Cancer and Nutrition (EPIC) study. European Journal of Cancer, 46, 2555-2562. doi:10.1016/j.ejca.2010.07.025

[5] Shukla, S., Bharti, A.C., Mahata, S., Hussain, S., Kumar, R., Hedau, S. and Das, B.C. (2009) Infection of human papillomaviruses in cancers of different human organ sites. Indian Journal of Medicine Research, 130, 222-233.

[6] Damin, A.P., Karam, R., Zettler, C.G., Caleffi, M. and Alexandre, C.O. (2004) Evidence for an association of human papillomavirus and breast carcinomas. Breast Cancer Research and Treament, 84, 131-137. doi:10.1023/B:BREA.0000018411.89667.0d

[7] De Villiers, E.M., Sandstrom, R.E., zur, H.H. and Buck, C.E. (2005) Presence of papillomavirus sequences in condy-lomatous lesions of the mamillae and in invasive carci-noma of the breast. Breast Cancer Research, 7, $1-11$.

[8] Heng, B., Glenn, W.K., Ye, Y., Tran, B., Delprado, W., Lutze-Mann, L., Whitaker, N.J. and Lawson, J.S. (2009) Human papilloma virus is associated with breast cancer. British Journal of Cancer, 101, 1345-1350. doi:10.1038/sj.bjc.6605282

[9] Lawson, J.S., Glenn, W.K., Heng, B., Ye, Y., Tran, B., Lutze-Mann, L. and Whitaker, N.J. (2009) Koilocytes indicate a role for human papilloma virus in breast cancer. British Journal of Cancer, 101, 1351-1356. doi:10.1038/sj.bjc.6605328

[10] Band, V., Zajchowski, D., Kulesa, V. and Sager, R. (1990) Human papilloma virus DNAs immortalize normal human mammary epithelial cells and reduce their growth factor requirements. Proceedings of the National Academy of Sciences of the United States of America, 87, 463-467. doi:10.1073/pnas.87.1.463

[11] Shai, A., Pitot, H.C. and Lambert, P.F. (2008) Loss syn- ergizes with estrogen and papillomaviral oncogenes to induce cervical and breast cancers. Cancer Research, 68, 2622-2631. doi:10.1158/0008-5472.CAN-07-5266

[12] Aceto, G.M., Solano, A.R., Neuman, M.I., Veschi, S., Morgano, A., Malatesta, S., Chacon, R.D., Pupareli, C., Lombardi, M., Battista, P., Marchetti, A., Mariani-Costantini, R. and Podesta, E.J. (2010) High-risk human papilloma virus infection, tumor pathophenotypes, and BRCA1/2 and TP53 status in juvenile breast cancer. Breast Cancer Research and Treatment, 122, 671-683. doi:10.1007/s10549-009-0596-6

[13] Hedau, S., Kumar, U., Hussain, S., Shukla, S., Pande, S., Jain, N., Tyagi, A., Deshpande, T., Bhat, D., Mir, M.M., Chakraborty, S., Singh, Y.M., Kumar, R., Somasundaram, K., Bharti, A.C. and Das, B.C. (2011) Breast cancer and human papillomavirus infection: No evidence of HPV etiology of breast cancer in Indian women. BMC Cancer, 11, 27. doi:10.1186/1471-2407-11-27

[14] Hachana, M., Ziadi, S., Amara, K., Toumi, I., Korbi, S. and Trimeche, M. (2010) No evidence of human papillomavirus DNA in breast carcinoma in Tunisian patients Breast Cancer, 19, 541-544.

[15] Tseng, C.K., Tsang, N.M., Kao, S.C., Chen, S.Y. and Chen, Y.P. (1998) A quick method to extract DNA from paraffin-embedded tissues. Changgeng Yi Xue Za Zhi, 21, 63-66.

[16] Baay, M.F., Quint, W.G., Koudstaal, J., Hollema, H., Duk, J.M., Burger, M.P., Stolz, E. and Herbrink, P. (1996) Comprehensive study of several general and type-specific primer pairs for detection of human papil- lomavirus DNA by PCR in paraffin-embedded cervical carcinomas. Journal of Clinical Microbiology, 34, 745-747.

[17] Forslund, O., Antonsson, A., Nordin, P., Stenquist, B. and Hansson, B.G. (1999) A broad range of human papillomavirus types detected with a general PCR method suitable for analysis of cutaneous tumours and normal skin. Journal of General Virology, 80, 2437-2443.

[18] Karlsen, F., Kalantari, M., Jenkins, A., Pettersen, E., Kristensen, G., Holm, R., Johansson, B. and Hagmar, B. (1996) Use of multiple PCR primer sets for optimal detection of human papillomavirus. Journal of Clinical Microbiology, 34, 2095-2100.

[19] Payan, C., Ducancelle, A., Aboubaker, M.H., Caer, J., Tapia, M., Chauvin, A., Peyronnet, D., Le, H.E., Arab, Z., Legrand, M.C., Tran, A., Postec, E., Tourmen, F., Avenel, M., Malbois, C., De Brux, M.A., Descamps, P. and Lunel, F. (2007) Human papillomavirus quantification in urine and cervical samples by using the Mx4000 and LightCycler general real-time PCR systems. Journal of Clinical Microbiology, 45, 897-901. doi:10.1128/JCM.02022-06

[20] Kleter, B., van Doorn, L.J., Ter, S.J., Schrauwen, L., van, K.K., Burger, M., Ter, H.B. and Quint, W. (1998) Novel short-fragment PCR assay for highly sensitive broadspectrum detection of anogenital human papillomaviruses. America Journal of Pathology, 153, 1731-1739. doi:10.1016/S0002-9440(10)65688-X

[21] Kulkarni, S.S., Kulkarni, S.S., Vastrad, P.P., Kulkarni, B.B., Markande, A.R., Kadakol, G.S., Hiremath, S.V., Kaliwal, S., Patil, B.R. and Gai, P.B. (2011) Prevalence and distribution of high risk human papillomavirus (HPV) types 16 and 18 in carcinoma of cervix, saliva of patients 
with oral squamous cell carcinoma and in the general population in Karnataka. India. Asian Pacific Journal of Cancer Prevention, 12, 645-648.

[22] Hennig, E.M., Suo, Z., Thoresen, S., Holm, R., Kvinnsland, S. and Nesland, J.M. (1999) Human papillomavirus 16 in breast cancer of women treated for high grade cervical intraepithelial neoplasia (CIN III). Breast Cancer Research and Treatment, 53, 121-135. doi:10.1023/A:1006162609420

[23] Wong, S.C., Au, T.C., Chan, S.C., Chan, C.M., Lam, M.Y., Zee, B.C., Pong, W.M. and Chan, A.T. (2010) Human papillomavirus DNA detection in menstrual blood from patients with cervical intraepithelial neoplasia and condyloma acuminatum. Journal of Clinical Microbiology, 48, 709-713. doi:10.1128/JCM.01996-09

[24] De Cremoux, P., Thioux, M., Lebigot, I., Sigal-Zafrani, B., Salmon, R. and Sastre-Garau, X. (2008) No evidence of human papillomavirus DNA sequences in invasive breast carcinoma. Breast Cancer Research and Treatment, 109, 55-58. doi:10.1007/s10549-007-9626-4

[25] Di, L.A., Venuti, A. and Marcante, M.L. (1992) Human papillomavirus in breast cancer. Breast Cancer Research and Treatment, 21, 95-100. doi:10.1007/BF01836955

[26] Czerwenka, K., Heuss, F., Hosmann, J.W., Manavi, M., Lu, Y., Jelincic, D. and Kubista, E. (1996) Human papilloma virus DNA: A factor in the pathogenesis of mammary Paget's disease? Breast Cancer Research and Treatment, 41, 51-57. doi:10.1007/BF01807036

[27] Bratthauer, G.L., Tavassoli, F.A. and O'Leary, T.J. (1992) Etiology of breast carcinoma: no apparent role for papillomavirus types. Pathology Research Practice, 188, 384386.

[28] Widschwendter, A., Brunhuber, T., Wiedemair, A., Mueller-Holzner, E. and Marth, C. (2004) Detection of human papillomavirus DNA in breast cancer of patients with cervical cancer history. Journal of Clinical Virology, 31, 292-297. doi:10.1016/j.jcv.2004.06.009

[29] Levin, M., Newport, M.J., D'Souza, S., Kalabalikis, P., Brown, I.N., Lenicker, H.M., Agius, P.V., Davies, E.G.,
Thrasher, A., Klein, N. (1995) Familial disseminated atypical mycobacterial infection in childhood: A human mycobacterial susceptibility gene? Lancet, 345, 79-83. doi:10.1016/S0140-6736(95)90059-4

[30] Levin, M. and Newport, M. (1999) Understanding the genetic basis of susceptibility to mycobacterial infection. Proceedings of the Association of American Physicians, 111, 308-312. doi:10.1046/j.1525-1381.1999.99242.x

[31] De Leon, D.C., Montiel, D.P., Nemcova, J., Mykyskova, I., Turcios, E., Villavicencio, V., Cetina, L., Coronel, A and Hes, O. (2009) Human papillomavirus (HPV) in breast tumors: Prevalence in a group of Mexican patients. BMC Cancer, 9, 26. doi:10.1186/1471-2407-9-26

[32] Khan, N.A., Castillo, A., Koriyama, C., Kijima, Y., Umekita, Y., Ohi, Y., Higashi, M., Sagara, Y., Yoshinaka, H., Tsuji, T., Natsugoe, S., Douchi, T., Eizuru, Y. and Akiba, S. (2008) Human papillomavirus detected in female breast carcinomas in Japan. British Journal of Cancer, 99, 408-414. doi:10.1038/sj.bjc.6604502

[33] Yu, Y., Morimoto, T., Sasa, M., Okazaki, K., Harada, Y., Fujiwara, T., Irie, Y., Takahashi, E., Tanigami, A. and Izumi, K. (2000) Human papillomavirus type 33 DNA in breast cancer in Chinese. Breast Cancer, 7, 33-36. doi:10.1007/BF02967185

[34] Hedau, S., Kumar, U., Hussain, S., Shukla, S., Pande, S., Jain, N., Tyagi, A., Deshpande, T., Bhat, D., Mir, M.M., Chakraborty, S., Singh, Y.M., Kumar, R., Somasundaram, K., Bharti, A.C. and Das, B.C. (2011) Breast cancer and human papillomavirus infection: No evidence of HPV etiology of breast cancer in Indian women. BMC Cancer, 11, 27. doi:10.1186/1471-2407-11-27

[35] Wrede, D., Luqmani, Y.A., Coombes, R.C. and Vousden, K.H. (1992) Absence of HPV 16 and 18 DNA in breast cancer. British Journal of Cancer, 65, 891-894. doi:10.1038/bjc.1992.186

[36] Lindel, K., Forster, A., Altermatt, H.J., Greiner, R. and Gruber, G. (2007) Breast cancer and human papillomavirus (HPV) infection: No evidence of a viral etiology in a group of swiss women. Breast Cancer, 16, 172-177. 